\title{
PARTICIPATION RATE OF EMPLOYEES OF RS X IN THE COVID-19 VACCINATION PROGRAM TO BREAK THE CHAIN THE SPREAD OF COVID-19
}

\author{
Kristianto \\ Master of Public Health Study Program, Faculty of Public Health \\ Muhammadiyah University of Jakarta \\ Jl. K.H. Ahmad Dahlan, Cireundeu, Kec. Ciputat, Kota Tangerang Selatan, Banten 15419 \\ E-mail: kris.karyabhakti@gmail.com
}

\begin{abstract}
The COVID-19 vaccination aims to reduce the transmission of COVID-19, reduce morbidity and mortality due to COVID-19, achieve herd immunity, and protect the community from COVID-19 to remain socially and economically productive. The role of social media in the era of digital technology can bring positive things as well as negative things, in a positive context there are invitations in the form of motivation to participate in vaccination programs. Meanwhile, in a negative context, the COVID-19 vaccination has become a cornering or scary hoax. However, this news cannot be verified. However, this news greatly influences a person's decision to participate or not in the vaccination program in addition to doubts about the safety of vaccines, doubts about the effectiveness of vaccines, distrust of vaccines, fears of side effects such as fever and pain, and religious reasons. This study will explain the level of participation of workers who work in Hospital $X$ in receiving a prioritized vaccination program for health workers. The research method used is descriptive, where data is collected in the period from January 29, 2021, to May 10, 2021. The vaccination program which is an alternative to breaking the chain of the spread of COVID-19 is welcomed by its implementation in Hospital $X$ with the participation rate of the results. reached $92 \%$. The remaining $8 \%$ were not vaccinated because they did not receive a recommendation from a doctor or refused the vaccine because they were worried about the side effects.
\end{abstract}

Keywords: Participation, Covid-19, Vaccination. 


\section{INTRODUCTION}

The government has declared the Coronavirus Disease 2019 (COVID-19) pandemic a nonnatural disaster. Since the announcement of the first confirmed case in March 2020, within one month, all provinces have reported confirmed cases. The spread of COVID-19 has not only occurred in the Special Capital Region of Jakarta and other densely populated cities but has spread to rural areas in remote areas. As of December 27, 2020, as many as 706,837 confirmed cases of COVID-19 have been reported in Indonesia and a total of 20,994 people have died.

The COVID-19 pandemic poses a major challenge in efforts to improve the health status of the Indonesian people and has an impact on the Indonesian health system as seen from the decline in performance in several health programs. This is due to the priority in overcoming the COVID-19 pandemic as well as the public and officers' concerns about the transmission of COVID-19. In some areas, the COVID-19 pandemic situation has even resulted in temporary closures and/or delays of health services, especially in Posyandu and Puskesmas.

The COVID-19 pandemic also had a major impact on the economy, namely: (1) Making people's purchasing power, which is the pillar of the economy by 60 percent, fall quite deeply. This is evidenced by data from BPS which recorded that household consumption fell from 5.02 percent in the first quarter of 2019 to 2.84 percent in the first quarter of 2020; (2) Causing a prolonged uncertainty in the business world so that investment also weakens and has implications for the cessation of business; and (3) the entire world experienced a weakening economy, causing commodity prices to fall and Indonesia's exports to several countries also stalling. In addition, the COVID-19 pandemic that hit the world also had a visible impact in various sectors including the social sector, tourism, and education.

Meanwhile, the level of community vulnerability is increasing due to a lack of public awareness of the implementation of health protocols such as wearing masks, washing hands, and maintaining a minimum distance of 1-2 meters. Without prompt and appropriate public health intervention, it is estimated that as many as 2.5 million cases of COVID-19 will require hospitalization in Indonesia with an estimated mortality rate of 250,000 deaths.

Since the COVID-19 disease entered and spread in Indonesia, all parties have begun to be alert and worried, especially health workers who feel greater concern, because it is well known that this health problem will inevitably lead to the hospital. This concern is true, it is proven that until midMay 2021 there were 128 employees (27.5\%) who were infected with COVID-19.

The role of social media in the era of digital technology can bring positive things as well as negative things, in a positive context there are invitations in the form of motivation to participate in vaccination programs. Meanwhile, in a negative context, the COVID-19 vaccination has become a 
cornering or scary hoax. However, this news cannot be verified. However, this news greatly influences a person's decision to participate or not in the vaccination program.

Besides that, COVID-19 is a newly emerging disease, so medicines including vaccines are also new products. This novelty makes there is not much convincing evidence of the efficacy of vaccine products, of course, this will create doubts from prospective vaccine recipients.

To overcome this disease, one of which is the need for immediate intervention not only in terms of implementing health protocols but also other effective interventions are needed to break the chain of disease transmission, namely through vaccination efforts. Efforts have been made by various countries, including Indonesia, to develop ideal vaccines for the prevention of SARS-CoV-2 infection with various platforms, namely inactivated virus vaccines, live attenuated virus vaccines, virus vector vaccines, nucleic acid vaccines., virus-like vaccines (virus-like vaccines), and protein subunit vaccines.

COVID-19 vaccination aims to reduce the transmission/transmission of COVID-19, reduce morbidity and mortality due to COVID-19, achieve group immunity in the community ( herd immunity) and protect the community from COVID-19 to remain socially and economically productive. Herd immunity can only be formed if vaccination coverage is high and evenly distributed throughout the region. Prevention efforts through the provision of vaccination programs if assessed from an economic point of view will be much more cost-effective when compared to treatment efforts.

Health workers are a priority to get vaccines from the government with consideration, health workers are workers who are vulnerable to COVID-19 disease because they work on the front lines in dealing with patients infected with COVID-19, so health workers must be completely protected so that they can play an optimal role. in his duties.

Hospital $\mathrm{X}$ is one of the hospitals located in Bogor that gets the priority in the government's COVID-19 Vaccination program for its employees.

This study will explain how the level of participation of workers who work in Hospital X in receiving a prioritized vaccination program for health workers in situations where many doubt this vaccination program.

\section{METHODS}

The research method used is descriptive, where the data collected in the period 29 January 2021 to 10 May 2021 are grouped and arranged so that they can be interpreted according to needs. Place of research in the hospital. X which is located in Bogor. The purpose of this study was to determine how big the level of participation of RS X employees in the COVID-19 vaccination program which was prioritized by the government for health workers. 


\section{RESULTS AND DISCUSSION}

The results of the research that has been carried out have produced the following data:

Table 1: Participation in COVID-19 Vaccination by Profession/Work Unit

\begin{tabular}{clccccc}
\hline NO & $\begin{array}{c}\text { PROFESSION/ } \\
\text { WORK UNIT }\end{array}$ & VACCINATED & NO & TOTAL & $\begin{array}{c}\text { \% } \\
\text { VACCINATED }\end{array}$ & $\begin{array}{c}\text { \% } \\
\text { NO }\end{array}$ \\
\hline 1 & radiology & 8 & 0 & 8 & 100 & 0 \\
\hline 2 & Medical record & 6 & 0 & 6 & 100 & 0 \\
\hline 3 & Cleaning Service & 30 & 0 & 30 & 100 & 0 \\
\hline 4 & Pharmacy & 39 & 1 & 40 & 98 & 2 \\
\hline 5 & Administration & 112 & 3 & 115 & 97 & 3 \\
\hline 6 & Nurses and Midwives & 153 & 17 & 170 & 90 & 10 \\
\hline 7 & Nutrition & 17 & 3 & 20 & 85 & 15 \\
\hline 8 & Courier & 11 & 2 & 13 & 85 & 15 \\
\hline 9 & Medical Rehab & 5 & 1 & 6 & 83 & 17 \\
\hline 10 & security guard & 20 & 5 & 25 & 80 & 20 \\
\hline 11 & Laboratory & 12 & 3 & 15 & 80 & 20 \\
\hline 12 & General practitioners & 13 & 4 & 17 & 76 & 24 \\
\hline & Amount & 426 & 39 & 465 & 92 & 8 \\
\hline
\end{tabular}

Table 2: Reasons for not being vaccinated against COVID-19 by Profession/Work Unit

\begin{tabular}{clccc}
\hline NO & $\begin{array}{c}\text { PROFESSION/ } \\
\text { WORK UNIT }\end{array}$ & REJECT & $\begin{array}{c}\text { NOT } \\
\text { RECOMMENDED }\end{array}$ & TOTAL \\
\hline 1 & Nurses and Midwives & 3 & 14 & 17 \\
\hline 2 & security guard & 3 & 2 & 5 \\
\hline 3 & General practitioners & 0 & 4 & 4 \\
\hline 4 & Administration & 0 & 3 & 3 \\
\hline 5 & Nutrition & 0 & 3 & 3 \\
\hline 6 & Laboratory & 0 & 3 & 3 \\
\hline 7 & Courier & 0 & 2 & 2 \\
\hline 8 & Pharmacy & 0 & 1 & 1 \\
\hline 9 & Medical Rehab & 0 & 1 & 0 \\
\hline 10 & radiology & 0 & 0 & 0 \\
\hline 11 & Medical record & 0 & 0 & 0 \\
\hline 12 & Cleaning Service & 0 & 0 & 39 \\
\hline & Amount & 6 & 33 & 1 \\
\hline
\end{tabular}

The participation rate of RS X employees in the COVID-19 vaccination program is illustrated by the data above, employees in the Radiology, Medical Record, and Cleaning Service work units/professions reached the maximum number, which was $100 \%$. This means that this work unit has all of its employees vaccinated against COVID-19. It can also mean that employees in this unit have confidence in the COVID-19 vaccination.

Employees in administrative work units, pharmacy, and nurses/midwives have a participation rate of $90 \%-98 \%$, while nutrition, courier, security guard, and laboratory medical rehabilitation units 
reach $80-85 \%$. This means that there are still employees who are not vaccinated on the grounds of refusing the vaccine or not receiving a recommendation from a doctor.

For general practitioners, the participation rate in the implementation of COVID-19 vaccination reaches $76 \%$ or the lowest, this is certainly very interesting because it is hoped that the medical profession will get a high participation rate. But in the data above, it turns out that the opposite is true. This happened not because of refusal but because it did not get a recommendation from a doctor, this would be natural because doctors would understand more about vaccination so they would be more careful if there was a disease that could cause AEFI (Post Immunization Adverse Events).

Indeed, not all employees participated in the COVID-19 vaccination, there were 39 people. Of the 29 people, 33 people were not vaccinated from January 31, 2021, to May 10, 2021, with the first reason not getting a recommendation from the examining doctor because they were suffering from illness, were pregnant, on long-term treatment, had been infected with COVID-19 and had not been 3 months from recovering. While the remaining 6 people refused to be vaccinated because they were worried about the side effects.

Another online study that was conducted from 19 to 30 September 2020 which was attended by more than 115,000 respondents from 34 provinces obtained results where the highest vaccine acceptance (69\%) came from respondents belonging to the middle class and the lowest (58\%) came from poor respondents. In general, the higher the economic status of the respondent, the higher the level of acceptance. However, the highest rejection was indicated by respondents belonging to the highest economic class (12\%) and the lowest was indicated by middle-class respondents (7\%). Onethird of respondents who are classified as poor have not decided to accept or reject the vaccine and the level of doubt tends to decrease with increasing economic status.

Meanwhile, the acceptance rate of the COVID-19 vaccine between male and female respondents was almost the same. $10 \%$ of male respondents said they refused to be vaccinated and less than five percent of female respondents said so. Furthermore, female respondents seemed more doubtful than male respondents.

The most common reasons for rejection of the COVID-19 vaccine were related to vaccine safety (30\%); doubts about the effectiveness of the vaccine (22\%); distrust of vaccines (13\%); concern about side effects such as fever and pain (12\%); and religious reasons $(8 \%)$.

Doubts arise from respondents who are afraid of needles and who have experienced side effects after being immunized. Several respondents questioned the vaccine clinical trial process and its safety. The reliability of vaccine providers is considered important and many have stated that they are willing to accept vaccines if Indonesia produces them. Respondents also expect political leaders to set an example, for example, by being the first to be vaccinated before mass vaccination is carried 
out. Many respondents do not believe that COVID-19 (SARS-CoV-2) is real or that it is possible to spread and threaten public health. Several respondents stated that the pandemic was a product of propaganda, conspiracy, hoax, and/or a deliberate attempt to spread fear through the media for profit.

Public perception of health and disease prevention is also an important factor; many respondents think that deepening spirituality is a way of maintaining health and dealing with the disease. Other general contextual factors such as religion, perceptions of pharmaceutical companies, and social, cultural, and economic conditions also influence vaccine acceptance. Some respondents thought that the recommendations for wearing masks, washing hands, and implementing social restrictions $(3 \mathrm{M})$ were sufficient. Respondents who actively followed 3M's recommendations felt that they had felt the benefits and questioned the risk-to-benefit ratio of using the vaccine.

So when comparing other studies that discuss vaccine acceptance in Indonesia, the results are in line, where there are still rejections for various reasons and one of them is refusing the vaccine because of concerns about the side effects it causes.

\section{CONCLUSION AND SUGGESTIONS}

The vaccination program, which is one of the alternatives to break the chain of the spread of the COVID-19 disease, was welcomed by its implementation at RS X with an employee participation rate of $92 \%$.

The remaining $8 \%$ were not vaccinated because they did not receive a recommendation from a doctor or refused the vaccine because they were worried about the side effects.

Vaccination against COVID-19 is one of the efforts that are considered the least expensive and considered the most effective and efficient in a pandemic situation. The coverage must continue to be expanded by providing massive education and extensive vaccination programs so that group immunity can be obtained as soon as possible which will eventually break the chain of transmission of the spread of COVID-19, especially in Indonesia in general in the world.

\section{REFERENCES}

1. Indonesian Ministry of Health, 2021, Decree of the Director-General of Disease Prevention and Control Number Hk.02.02/4/ 1 /2021 concerning Technical Guidelines for Vaccination Implementation in the Context of Combating the Corona Virus Disease 2019 (COVID-19) Pandemic

2. Iris Rengganis, COVID-19 Vaccination, PAPDI

3. Indonesian Ministry of Health, 2020, Survey on receipt of COVID-19 Vaccination.

4. Rahmi Yuningsih, Coronavirus Clinical Trials and Covid-19 vaccination plans in Indonesia, Research Center of the Indonesian House of Representatives Expertise Board Gd. Nusantara I Lt. 2 Jl. Gen. Gatot Subroto Central Jakarta - 10270 
5. dr. Gisheila Ruth Anggitha, Safety and Efficacy of the COVID-19 Vaccine BNT162b2 MRNA—Alomedika Journal Review 